Journal of Reproduction and Development, Vol. 39, No. 1, 1993

\title{
Isolation of the Mouse Ren-1C Gene and Characterization of Renin Gene Expression in Both ES-D3 Cells and Their Parental Mouse Strain
}

\author{
Keiji TANIMOTO, Kouichi TAMURA, \\ Fumihiro SUGIYAMA ${ }^{1}$, Kazuo MURAKAMI and \\ Akiyoshi FUKAMIZU \\ Institute of Applied Biochemistry and \\ 1)Laboratory Animal Research Center, \\ University of Tsukuba, Tsukuba, Ibaraki 305, Japan
}

\begin{abstract}
Renin is the rate-limiting enzyme in the renin-angiotensin system, the only known biochemical cascade that produces the potent octapeptide effector molecule angiotensin II that controls, to a large degree, cardiovascular homeostasis and reproductive function in mammals. In the present study, we have cloned the Ren-1C gene from the C57BL/6 mouse and determined its genomic structure. In order to provide the molecular basis for the application of the gene targeting method to the renin gene, we also characterized the structure and expression of the renin gene in embryonic stem D-3 (ES-D3) cells and in its parental mouse strains, 129/Sv mouse. The Ren-1C gene is 12 kilobases long and is composed of 9 exons interrupted by 8 introns. Renin mRNA was undetectable in ES-D3 cells but was found to be highly expressed in the submandibular gland of the 129/Sv mouse, in addition to the kidney. Southern blot analysis reveals that ES-D3 cells carry the additional duplicated renin gene, Ren-2, consistent with the classification of the 129/Sv mouse as a two-renin gene strain. Key words: Renin, ES-D3 cells, Geue structure, Gene expression.
\end{abstract}

(J. Reprod. Dev. 39: 19-24, 1993)

$\mathbf{R}$ enin, an aspartyl proteinase synthesized mainly in the kidney, is the rate-limiting factor in the renin-angiotensin system, which is well known for its role as a systemic regulator of blood pressure and fluid homeostasis [1]. This system operates via the cleavage of circulating angiotensinogen by renin to produce angiotensin I which is in turn acted upon by angiotensin-converting enzyme to produce the active octapeptide, angiotensin II. In addition to its endocrine role, the renin-angiotensin system may also function in a paracrine manner, as components of the renin biochemical cascade have recently been reported in many organs, particularly in those concerned with cardiovascular and reproductive function [2]. Reproductive organs in which renin-angiotensin

Accepted for Publication: November 14, 1992

Correspondence: A. Fukamizu system components have been described include the ovary, testis, uterus and prostate gland [3-5]. High levels of angiotensin II have been found in the rat ovary and various specific receptors have been localized to several ovarian structures [5]. Furthermore, administration of the angiotensin II antagonist, saralasin, has been shown to block rat ovulation, suggesting the possible involvement of the renin-angiotensin system in the ovulatory process [6]. Thus renin, through the control of angiotensin II synthesis, is thought to play an important role in many physiologic processes.

Although the renin gene for rat and human exists in the genome as a single copy, mice have been known for some time to be polymorphic in respect to the number of renin genes. All inbred strains of mice commonly carry the Ren-1 renin gene and some strains of mice such as $\mathrm{DBA} / 2$, 
AKR and Swiss possess two renin genes, Ren- 1 and Ren-2. The 2 common alleles of the Ren-1 locus are designated by their origin: Ren-1C is the renin gene in strains containing a single renin locus and Ren-1D is the gene in strains bearing 2 renin loci. Despite the fact that Ren-1C and Ren-2 compared to Ren-1D display $98 \%$ and $96 \%[7,8]$ sequence identity at the cDNA level, respectively, each renin gene exhibits a unique pattern of tissue-specific expression. Ren-1C is expressed mainly in the kidney, with only weak expression in the submandibular gland (SMG) and none in the adrenal [9]. Although Ren-1D and Ren-2 are expressed at approximately equal levels in the kidney and adrenal, Ren-2 gene expression in the SMG is approximately 100 -fold higher than that of the Ren-1D gene [9, 10].

The production of transgenic animals by pronuclear microinjection has provided a particularly powerful approach not only for studying the regulation of gene expression in mammalian development, but also in studying reproductive endocrinology [11-13]. The use of homologydependent recombination between chromosomal DNA and exogenous DNA sequences in the method of gene targeting has offered a further dimension to transgenic technology. This approach employs pluripotent blastocyst-derived mouse embryonic stem (ES) cells [14] which are utilized for the introduction of selected targeted mutations into the mouse germ-line. As a first step in the in vivo analysis of mutants carrying lesions within the Ren-1C gene we have chosen the $\mathrm{C} 57 \mathrm{BL} / 6$ strain as a cloning source and have subsequently isolated the Ren-1C gene. Furthermore, we have characterized the structure of this renin gene and have examined its expression in ES-D3 cells, which are commonly used in gene targeting experiments $[15,16]$, as well as in the donor $129 / \mathrm{Sv}$ strain by blot hybridization analyses.

\section{Materials and Methods}

\section{Isolation of Ren-1C genomic clones}

A mouse genomic DNA library was constructed as a partial Sau3AI digest of C57BL/6 DNA cloned into bacteriophage $\lambda$ Charon 28. Plaque hybridization was performed using a ${ }^{32} \mathrm{P}$-labelled 816 -base pair (bp) KpnI/NcoI Ren-2 cDNA fragment [17] as a probe. DNA restriction fragments were subcloned into plasmid vectors and sequenced by the dideoxy-chain termination method [18].

\section{Northern and Southern blot analyses}

Total RNAs were extracted from liver, SMG and kidney of the 129/Sv mouse and the ES-D3 cell line and were denatured with $1 \mathrm{M}$ glyoxal and 50\% dimethyl sulfoxide followed by electrophoresis on a $1.2 \%$ agarose gel and transferred to a GeneScreen Plus membrane. Mouse genomic DNAs were extracted from C57BL/6 and 129/Sv strains and were digested by $E c o \mathrm{RI}$, electrophoresed on a $0.7 \%$ agarose gel, and transferred to a GeneScreen Plus membrane. Hybridization was performed using a ${ }^{32}$ P-labelled mouse Ren- 2 cDNA probe [17].

\section{Results}

\section{Isolation of the Ren-1C gene}

The C57BL/6 mouse genomic library generated represents a collection of recombinant phages produced by inserting partial Sau3AI digest products of liver genomic DNA between the BamHI sites of the arms of $\lambda$ Charon 28 . Through plaque screening by the use of a mouse Ren-2 cDNA probe [17], we have isolated 3 overlapping phage clones, designated as $\lambda \mathrm{mRn}-1, \lambda \mathrm{mRn}-2$, and $\lambda \mathrm{mRn}-3$ (Fig. 1), that in total contain the entire Ren-1C gene. Detailed restriction endonuclease mapping and partial sequence analysis revealed that the positions of various restriction endonucleases including EcoRI and HindIII as well as $K p n I$ of the C57BL/6 Ren-1C gene are identical to those of the Ren-1D and Ren-2 genes from the DBA/2 mouse strain [7] and that the 5'-flanking region extending from nucleotides -187 to +18 in the Ren-1C gene exhibits striking sequence similarity to those of the Ren-1D (99.5\% identity) and Ren-2 (91.2\% identity) genes (data not shown). The locations of the exons and introns of the Ren-1C gene were able to be deduced both by comparison with the restriction enzyme sites of the DBA/2 mouse renin genes (Fig. 1) and by partial sequence analysis (data not shown).

\section{Northern blot analysis}

As ES-D3 cells, derived from murine strain $129 / \mathrm{Sv}$, are now commonly used for establishing 

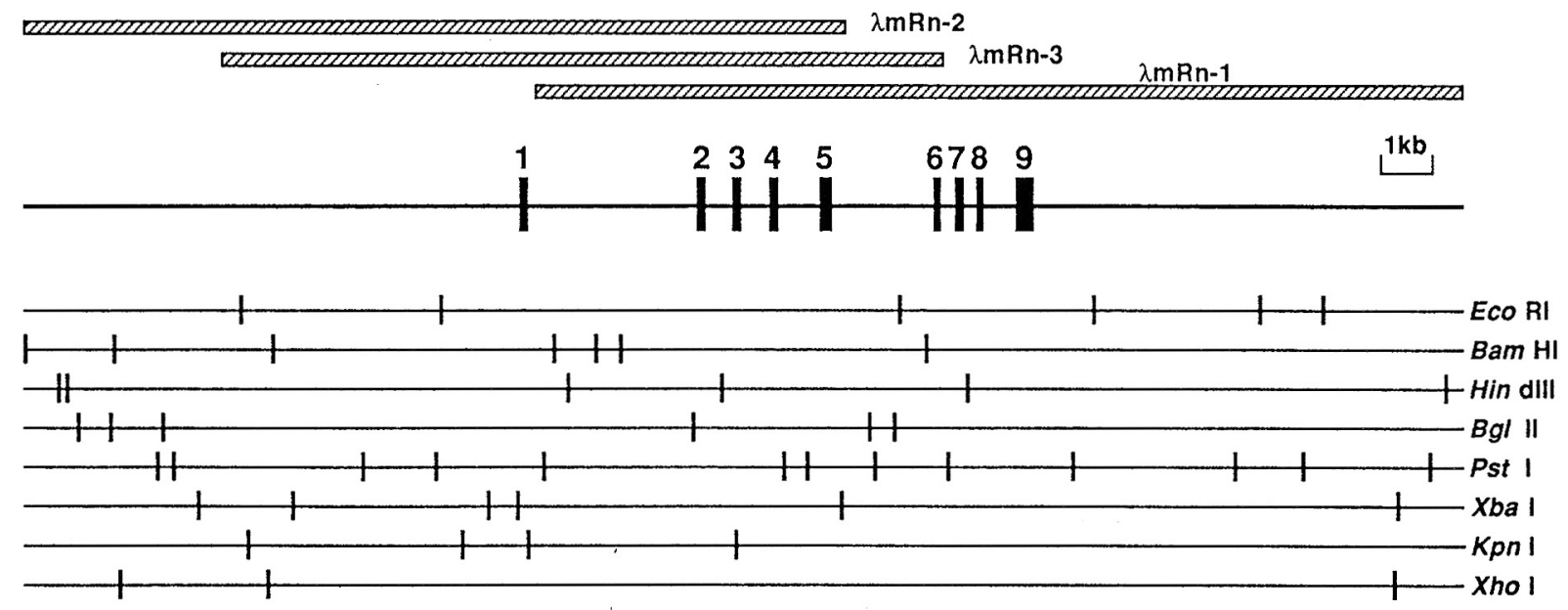

Fig. 1. Restriction map of the mouse Ren-1C gene. Three overlapping phage clones, $\lambda \mathrm{mRn}-1, \lambda \mathrm{mRn}-2$ and $\lambda \mathrm{mRn}-3$, were isolated from a C57BL/6 mouse genomic DNA library. Exons are depicted by the filled-in boxes and intronic sequences are represented by the joining thin horizontal line. The locations of accompanying restriction enzyme recognition sites are shown by vertical bars.

cell lines that contain a mutation at a specific site within a chromosome by the gene targeting approach $[15,16]$, we have attempted to determine the level of renin gene expression in these cells in addition to investigating the expression levels in the SMG and kidney of the donor mouse strain, 129/Sv. The latter investigation is prompted by the observation that there exist characteristic marked differences in tissue- and sex-specific expression of the renin genes in strains bearing two renin genes. In such strains, Ren-2-derived mRNA accumulates in the male SMG to an approximately 50 -fold higher level than that of the female with the level of renin gene expression in the kidney being 2-fold greater in the female than in the male [19]. Therefore, we have extracted total RNAs from liver (negative control), SMG and kidney of the 129/Sv mouse as well as from ES-D3 cells and have performed Northern blot analysis. Fig.2 shows that the level of renin mRNA in the $129 / \mathrm{Sv}$ strain is considerably higher in the male SMG (lane 5) than in that of the female (lane 2). In the same strain, however, the level of kidney renin mRNA is approximately 2-fold higher in the female (lane 3) than that in the male (lane 6). On the other hand, ES-D3 cells did not display any synthesis of renin mRNA (lanes 7 and 8). Under similar Northern hybridization conditions, SMG RNA from the C57BL/6 mouse did not produce any detectable hybridization signal (data not shown).

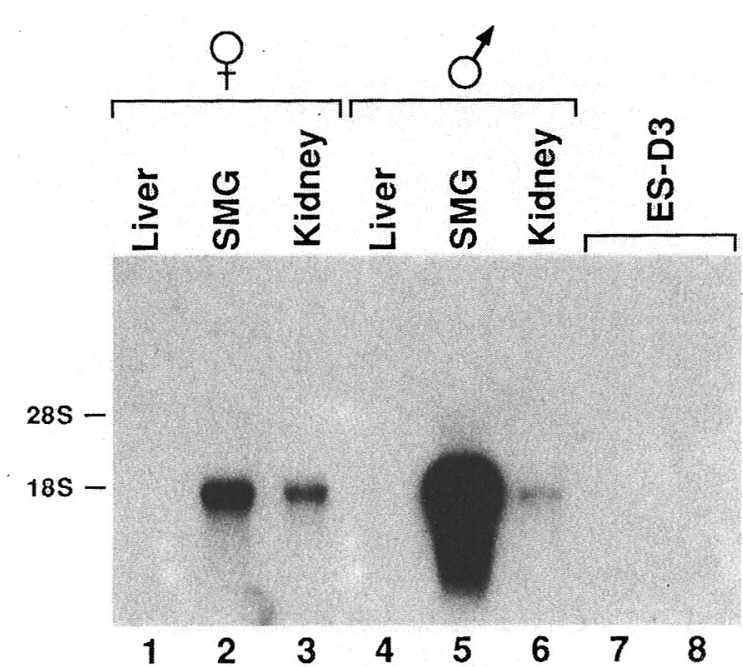

Fig. 2. Analysis of renin gene expression. Tissue preparations from female (lanes 1 to 3 ) and male (lanes 4 to 6) $129 / \mathrm{Sv}$ mice along with extracts from ES-D3 cells (lanes 7 and 8) were used as sources of RNA. Total RNA (lanes 1 to 7, $15 \mu \mathrm{g}$; lane 8, 30 $\mu \mathrm{g})$ was subjected to Northern blot analysis using a ${ }^{32}$ P-labelled mouse Ren-2 cDNA probe [17]. The positions of the $28 \mathrm{~S}$ and $18 \mathrm{~S}$ ribosomal RNA markers are indicated.

\section{Southern blot analysis}

The above Northern blot analysis is consistent with the existence of an additional renin gene, Ren-2, in strain 129/Sv. As ES-D3 failed to synthesize any significant amount of renin mRNA we performed Southern blot analysis on genomic DNA extracted from this cell line in order to establish whether or not ES-D3 cells possess 1 


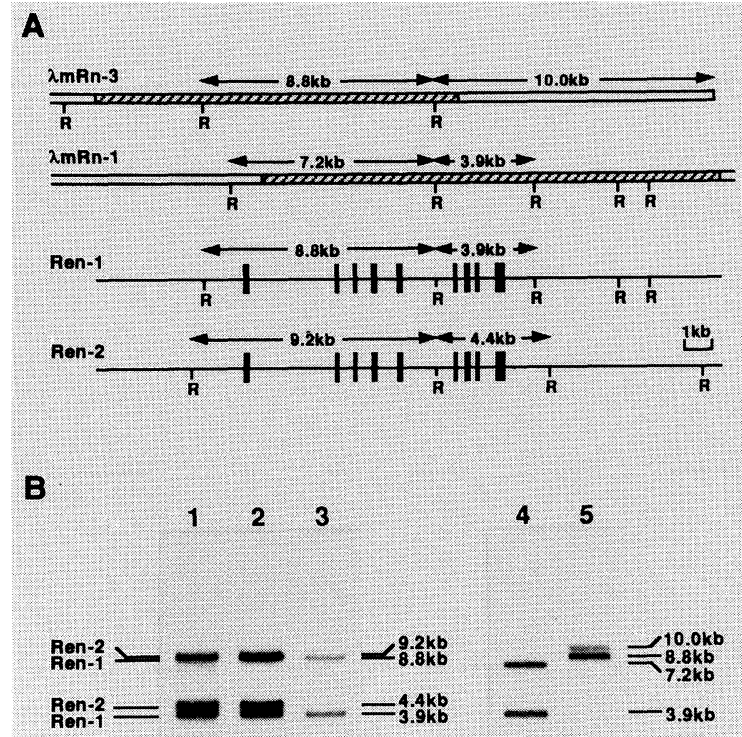

Fig. 3. (A) Organization of mouse renin genes. Hatched boxes represent Sau3AI DNA fragments inserted into $\lambda$ Charon 28 forming $\lambda \mathrm{mRn}-1$ and $\lambda \mathrm{mRn}-3$. The nine exons are shown by the filled-in boxes with adjoining intronic sequences represented by the thin horizontal line. The EcoRI (R) DNA fragments detected by Southern analysis are depicted by the double arrow lines with the fragment sizes as indicated. (B) Southern blot analysis of mouse renin genes. Two micrograms of tail DNA (lanes 1 and 3) and ES-D3 cell DNA (lane 2) and $0.2 \mathrm{ng}$ of recombinant phage DNA (lanes 4 and 5) were digested with EcoRI followed by electrophoresis on a $0.7 \%$ agarose gel and transferred to a nylon membrane. Lane 1, DBA/2 DNA (two-renin gene strain); lane 2, ES-D3 cell DNA (derived from strain 129/Sv); lane 3, C57BL/6 DNA (one-renin gene strain); lane $4, \lambda \mathrm{mRn}-1$ DNA; lane $5, \lambda \mathrm{mRn}-3$ DNA. Sizes of detected bands are shown on the right side of each gel.

renin gene or 2 renin genes. This method of approach was employed since on the basis of EcoRI hybridization patterns strains of mice bearing either 1 or 2 renin genes can be readily distinguished (Fig. 3A) [20]. For comparison, we used genomic DNAs from DBA/2 and C57BL/6 mice and phage DNAs from $\lambda \mathrm{mRn}-1$ and $\lambda \mathrm{mRn}-3$. As shown in Fig. 3B, genomic DNA extracted from the one-gene mouse, $\mathrm{C} 57 \mathrm{BL} / 6$, gave rise to 2 bands of 8.8 and $3.9 \mathrm{~kb}$ (lane 3 ) that represent the Ren-1C gene, while DNA extracted from the two-gene mouse, DBA/2, and ES-D3 cells gave rise to 2 additional hybridization bands of 9.2 and 4.4 $\mathrm{kb}$ (lanes 1 and 2) representing the Ren-2 gene. The cloned Ren-1C gene carried on phages $\lambda \mathrm{mRn}$ -
1 and $\lambda \mathrm{mRn}-3$ also exhibited 2 bands of 8.8 and $3.9 \mathrm{~kb}$ (Fig. 2A, and lanes 4 and 5 of Fig. 3B), although additional bands of 10 and $7.2 \mathrm{~kb}$ derived from the cloning vector were also observed. These results are consistent with the fact that ES-D3 cells possess 2 renin genes, viz. Ren-1D and Ren-2. Therefore, these data in combination with Northern analyses support the conclusion that the $129 / \mathrm{Sv}$ mouse strain carries both the Ren-1D and Ren-2 genes.

\section{Discussion}

In the present study, we have cloned the Ren-1C gene from a C57BL/6 mouse genomic DNA library and have determined its structure. As expected, the exon-intron arrangement (9 exons and 8 introns) of the Ren-1 C gene (Fig. 1) is very similar to that of both the Ren-1D and Ren-2 genes [7] as well as that of the rat renin gene [21]. Despite the fact that the Ren-1D and Ren-2 genes have been widely used in the production of a number of transgenic animals [9, 10, 22], the Ren-1C gene has not been similarly examined. In the case of Ren-2, Mullins et al. [22] have demonstrated that transgenic rats carrying this gene exhibit fulminant hypertension, evidence which represents a divergence away from the long standing belief that only the Ren-1C and Ren-1D genes expressed mainly in the kidney play the major role in blood pressure regulation [23]. These results are suggestive of the possible involvement of the Ren-2 gene in the pathogenesis of high blood pressure. In contrast to these data, the Ren-2 gene when introduced into mice with a Ren-1C genetic background did not lead to the development of hypertension [9, 10]. At present, the reason for the different effects of Ren-2 action between the 2 species, rat and mouse, is poorly understood and therefore future investigations aimed at understanding these differences are likely to focus on altering the host's genetic background by the use of the gene targeting approach. One important candidate for this approach is the Ren-1C gene which may possibly be mutated by the targeting method and thereby further our knowledge of host regulation in the genesis of hypertension.

It has generally been accepted that the frequency of gene targeting is strongly dependent upon 
the extent of homology between the targeting, or mutated DNA construct, and the locus targeted [24-26]. For example, a 2-fold increase in the extent of homology results in a 20 -fold increase in the frequency of targeting [24]. Further studies have indicated that constructs prepared with vector DNA isolated from strains of mice from which the recipient ES cell line was derived (isogenic DNA) targeted 4 to 20 times more efficiently than did the same construct bearing vector DNA derived from an unrelated mouse strain (nonisogenic DNA) [25, 26]. Besides the overall degree of homology and vector source, individual basepair variation may, in addition, affect the rate of homologous recombination. In this regard, Letsou and Liskay [27] have shown that the frequency of intrachromosomal gene conversion is sensitive to even a single base-pair mismatch within a $1-\mathrm{kb}$ interval.

Interestingly, Miller et al. [28] have recently reported that a Ren-1D targeting vactor homologously recombined only with the Ren-1D locus of EK-CP1 ES cells which possess both the Ren-1D and Ren-2 genes. This is in spite of the fact that both renin loci are highly homologous. It can therefore be anticipated that in the Ren-1D targeted EK-CP1 transgenic mouse renin activity may not be greatly altered as compared with the wild-type due to the presence of the fully active Ren-2 locus. Likewise, one can predict that the Ren-1D gene borne on a vector derived from two-renin gene ES cells would poorly recombine with the Ren-1C gene of ES cells originating from mice carrying a single renin gene on the grounds of homology constraints and the nonisogenic source of the gene. Therefore, in order to perform efficient Ren-1C gene targeting and thus assess the involvement of this gene in bloodpressure homeostasis and reproductive function, it is necessary to prepare mutants of Ren-1C on a vector derived from single renin gene ES cells and thereby effectively introduce these constructs into an ES cell line originating from a one-gene mouse strain.

As judged by Northern blot analysis (Fig. 2), we were unable to detect mouse renin mRNA in ES-D3 cells derived from the $129 / \mathrm{Sv}$ mouse. Nevertheless, the present study has shown that in this strain there is a considerable amount of renin mRNA present in the SMG as well as in the kidney. Since a high level of expression of the renin gene in the SMG is diagnostic for the presence of two renin genes, as such is the case with the DBA/2 strain [19], the expression results suggest that like this strain the $129 / \mathrm{Sv}$ mouse possesses 2 renin genes, viz. Ren-1D and Ren-2. Southern blot analyses (Fig. 3) are consistent with this concept.

Thus in summary, this study has shown that ES-D3 cells carry both the Ren-1D and Ren-2 genes by Northern and Southern blot analyses. In contrast to the ES-D3 cell line, Ledermann and Bürki [29] have established an ES cell line derived from the C57BL/6 mouse which can be used in gene targeting experiments aimed at examining the functional role of the Ren-1C gene. To this end, the cloned Ren-1C gene from strain C57BL/6 described in the present study will be of great assistance in that efficient recombination and thus effective gene targeting should be able to be realized on the basis of the ideal homology match.

\section{Acknowledgements}

We are grateful to Dr. Rolf Kemler and Professor Motoya Katsuki for their generous gifts of the ES-D3 cell line and mouse strain 129/Sv, respectively. We also thank Dr. John A. Loudon for his critical reading of this manuscript. This work was supported by grants from the Ministry of Education, Science and Culture of Japan, Chichibu Cement Co., Ltd., and Special Research Project on Circulation Biosystems at the University of Tsukuba. 


\section{References}

1. Peach MJ. Renin-angiotensin system: biochemistry and mechanisms of action. Physiol Rev 1977; 57: 313-370.

2. Campell DJ. Circulating and tissue angiotensin system. J Clin Invest 1987; 79: 1-6.

3. Naruse K, Murakoshi RY, Naruse M, Toma H, Watanabe K, Demura H, Inagami T, Shizume K. Immunohistological evidence for renin in human endocrine tissues. J Clin Endocrinol Metab 1985; 61: 172-177.

4. Kim S-J, Shinjo M, Fukamizu A, Miyazaki H, Usuki S, Murakami K. Identification of renin and renin messenger RNA sequence in rat ovary and uterus. Biochem Biophys Res Commun 1987; 142: 169-175.

5. Husain A, Bumpus FM, De Silva P, Speth RC. Localization of angiotensin II receptors in ovarian follicles and the identification of angiotensin II in rat ovaries. Proc Natl Acad Sci USA 1987; 261: 2489-2493.

6. Pellicer A, Palumbo A, DeCherney AH, Naftolin F. Blockage of ovulation by an angiotensin antagonist. Science 1988; 240: 1660-1661.

7. Holm I, Ollo R, Panthier J-J, Rougeon F. Evolution of aspartyl proteases by gene duplication: the mouse renin gene is organized in two homologous clusters of four exons. EMBO J 1984; 3: 557-562.

8. Abel KJ, Gross KW. Close physical linkage of the murine Ren-1 and Ren-2 loci. Nucleic Acids Res 1988; 16: 2111-2126.

9. Mullins JJ, Sigmund CD, Kane-Haas C, Gross KW. Expression of the DBA/2 Ren-2 gene in the adrenal gland of transgenic mice. $E M B O J$ 1989; 8: 4065-4072.

10. Sigmund CD, Gross KW. Structure, expression, and regulation of the murine renin genes. Hypertension 1991; 18: 446-457.

11. Palmiter RD, Brinster RF. Germ-line transformation of mice. Annu Rev Genet 1986; 20: 465-499.

12. Mason AJ, Pitts SL, Nikolics K, Szonyi E, Wilcox JN, Seeburg PH, Stewart TA. The hypogonadal mouse: reproductive functions restored by gene therapy. Science 1986; 234: 1372-1378.

13. Fukamizu A. Transgenic animals in endocrinological investigation. J Endocrinol Invest 1993 in press.

14. Cappecchi MR. Altering the genome by homologous recombination. Science 1989; 244: 1288-1292.

15. Doetschman TC, Eistetter H, Katz M, Schmidt W, Kemler R. The in vitro development of blastocystderived embryonic stem cell lines: formation of visceral yolk sac, blood islands and myocardium. $J$ Embryol Exp Morph 1985; 87: 27-45.
16. Gossler A, Doetschman T, Korn R, Serfling E, Kemler R. Transgenesis by means of blastocystderived embryonic stem cell lines. Proc Natl Acad Sci USA 1986; 83: 9065-9069.

17. Masuda T, Imai T, Fukushi T, Sudoh M, Hirose S, Murakami K. Molecular cloning of DNA complementary to mouse submandibular gland renin mRNA. Biomed Res 1982; 3: 541-545.

18. Sanger F, Nicklen S, Coulson AR. DNA sequencing with chain-terminating inhibitors. Proc Natl Acad Sci USA 1977; 74: 5463-5467.

19. Catanzaro DF, Mesterovic N, Morris BJ. Studies of the regulation of mouse renin genes by measurement of renin messenger ribonucleic acid. Endocrinology 1985; 117: 872-878.

20. Pantier J-J, Holm I, Rougeon F. The mouse Rn locus: $\mathrm{S}$ allele of the renin regulator gene results from a single structural gene duplication. $E M B O J$ 1982; 1: 1417-1421.

21. Fukamizu A, Nishi K, Cho T, Saitoh M, Nakayama K, Ohkubo H, Nakanishi S, Murakami K. Structure of the rat renin gene. J Mol Biol 1988; 201: 443-450.

22. Mullins JJ, Peters J, Ganten D. Fulminant hypertension in transgenic rats harbouring the mouse Ren-2 gene. Nature 1990; 344: 541-544.

23. Bing J, Poulsen K, Hackenthal E, Rix E, Taugner R. Renin in the submaxillary gland: a review. $J$ Histochem Cytochem 1980; 28: 874-880.

24. Thomas KR, Capecchi MR. Site-directed mutagenesis by gene targeting in mouse embryoderived stem cells. Cell 1987; 51: 503-512.

25. te Riele H, Maandag ER, Berns A. Highly efficient gene targeting in embryonic stem cells through homologous recombination with isogenic DNA constructs. Proc Natl Acad Sci USA 1992; 89: 5128-5132.

26. Deng C, Cappecchi MR. Reexamination of gene targeting frequency as a function of the extent of homology between the targeting vector and the target locus. Mol Cell Biol 1992; 12: 3365-3371.

27. Letsou A, Liskay M. Effect of the molecular nature of mutation on the efficiency of intrachromosomal gene conversion in mouse cells. Genomics 1987; 117: 759-769.

28. Miller CCJ, McPheat JC, Potts WJ. Targeted integration of the Ren-1D locus in mouse embryonic stem cells. Proc Natl Acad Sci USA 1992; 89: 5020-5024.

29. Ledermann B, Bürki K. Establishment of a germline competent C57BL/6 embryonic stem cell line. Exp Cell Res 1991; 197: 254-258. 